УДК 621.774 .37

Кравченко А. В.

\title{
ОСОБЕННОСТИ ОСНОВНЫХ ТЕХНОЛОГИЧЕСКИХ И КОНСТРУКТИВНЫХ ПАРАМЕТРОВ СТАЦИОНАРНОЙ КЛЕТИ СТАНА ХПТР ДЛЯ ПРОКАТКИ ПРЕЦИЗИОННЫХ ТЕПЛООБМЕННЫХ ТРУБ
}

В настоящее время широкое распространение получили станы ХПТР конструкции бывшего ВНИИМетмаша. Достоинствами этих станов являются малый размер и простота рабочего инструмента, определяющего общий относительно небольшой вес клети и ее большие технологические возможности при производстве труб. На трубных заводах бывшего СССР эти станы являются основными в производстве прецизионных теплообменных труб, в том числе и для корпусов ТВЭЛов из циркониевых, никелевых и титановых сплавов, труб для теплопоглощающих сборок и т. д.

Исследования в ряде работ $[1,2,3,4]$ показало, что производительность станов ХПТР не лимитируется силовыми параметрами и пластичностью металла, а в основном сдерживается допустимыми обжатиями в мгновенном очаге деформации с точки зрения обеспечения требуемого качества поверхности и точности геометрических размеров труб и возможностями подающе-поворотного механизма с мальтийским крестом.

Относительно низкая производительность действующих станов ХПТР в значительной степени объясняется малой длиной обжимной зоны, что связано с кинематикой клети, согласно которой длина хода сепаратора составляет около 60 \% от длины хода обоймы клети, приводимой в движение кривошипно-шатунным механизмом [5].

Конструктивные решения, такие как использование валковых клетей с опорными валками или опорными плитами, пока не имеют производственных перспектив в связи со сложностью конструкции самой клети, а также сложностью изготовления рабочего инструмента и перевалкой/настройкой стана. Современные валковые клети требуют сложного в изготовлении, дорого рабочего инструмента, обладающего низкой стойкостью [5].

Целью статьи является определение основных особенностей конструкции стационарной клети стана ХПТР для прокатки прецизионных теплообменных труб, у которой ход сепаратора с рабочими роликами был бы равен ходу обоймы.

Такое конструктивное исполнение можно представить в виде неподвижной обоймы и подвижного сепаратора, привод которого осуществляется непосредственно от кривошипнно-шатунного механизма.

Особенностью конструкции стационарной клети является наличие (рис. 1) опорных катков 1, установленных вместе с рабочими роликами 2 в подвижном сепараторе 3. Опорные планки 4 с регулировочными клиньями 5 закрепляются в неподвижной толстостенной обойме 6. Каждая опорная планка находится в контакте с двумя поясками опорного катка большего диаметра, а два пояска катка меньшего диаметра, контактируются с цапфами ролика.

Кроме увеличения длины обжимной зоны, такое решение позволяет существенно снизить вес подвижных частей клети, создавая возможности для увеличения числа двойных ходов сепаратора в минуту.

Кроме того, вследствие возможности увеличения толщины стенки неподвижной обоймы уменьшается ее упругая деформация и, следовательно, повысится точность прокатываемых труб. 


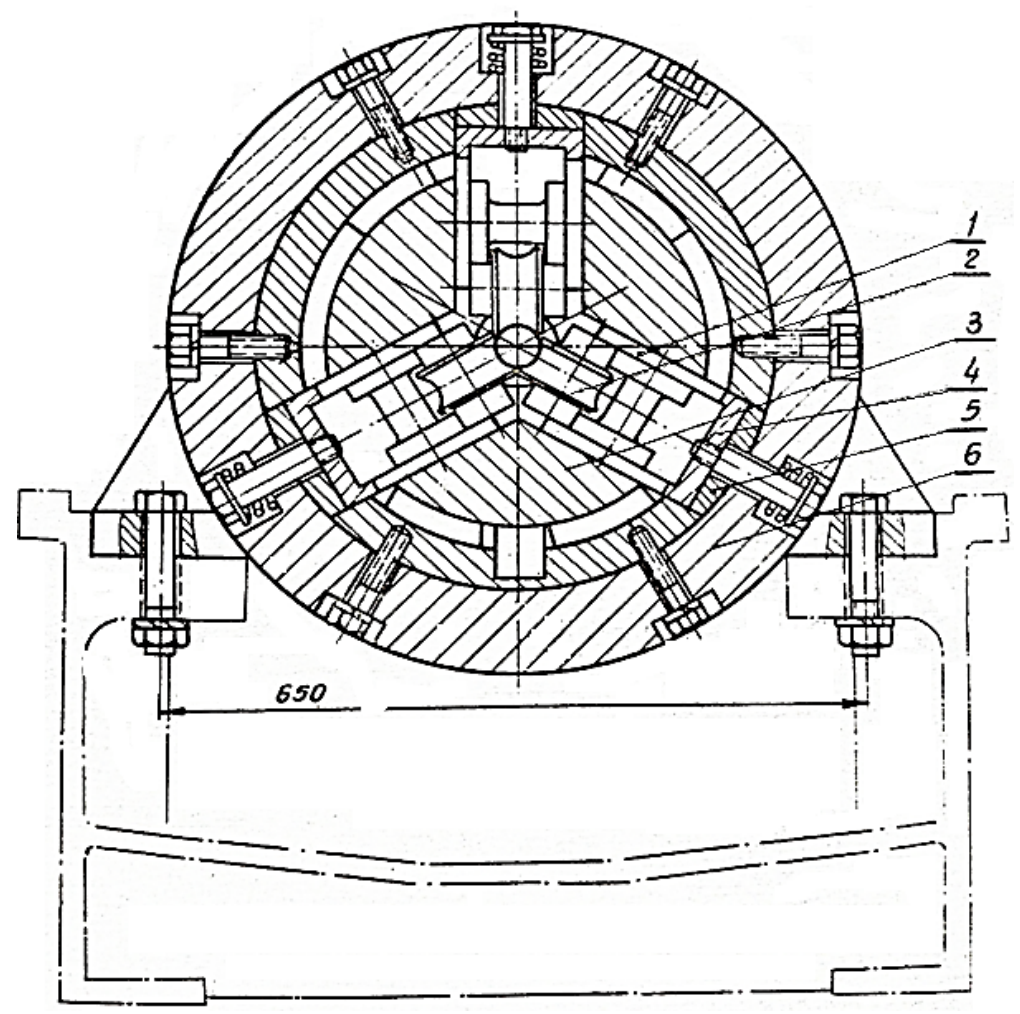

Рис. 1. Разрез стационарной клети стана ХПТР 15-30:

1 -опорные катки; 2-рабочие ролики, 3-сепаратор; 4-опорные планки; 5 - регулировочные клинья, 6 - неподвижная обойма

Увеличение длины обжимной или рабочей зон деформации позволяет прямопропорционально повысить величину подачи заготовки. Также увеличение длины рабочей зоны приводит к уменьшению деформаций в мгновенном очаге деформации. Последнее позволяет увеличить подачу и суммарные деформации в маршрутах прокатки. С ростом длины обжимной зоны уменьшается полное давление металла на ролик и увеличивается дробность деформации.

Значительное увеличение длины хода сепаратора и снижение веса подвижных частей клети (что особенно важно для станов ХПТР больших типоразмеров) существенно расширяет технологические возможности рассматриваемой клети.

Установка на действующие станы ХПТР такой клети возможна без изменения всех остальных механизмов стана, т. е. она связана с небольшими капитальными затратами.

Разработку конструкции клети стационарного типа выполнили применительно к стану ХПТР 15-30, так как этот типоразмер стана наиболее распространен на трубных заводах и занимает порядка 55 \% всех станов.

Предварительные расчеты показали, что стационарные клети для всех типоразмеров станов ХПТР обладают меньшим примерно в два раза весом подвижных частей при большей в 1,70 раза длине хода сепаратора, обеспечивая снижение удельного расхода энергии на прокатку труб и мощности главного привода стана, а также позволяя достичь производительности, превышающую в десятки раз исходную.

Стационарная клеть стана ХПТР (рис. 2) состоит из неподвижной обоймы 1 , представляющей собой толстостенный цилиндр, в котором установлены клинья 2, опорные планки 3 , три сегмента 4,5,6 и устройство для регулировки толщины стенки трубы путем одновременного перемещения клиньев, состоящее из зубчатой пары 18-19 и резьбового кольца 20. Внутри обоймы перемещается сепаратор 7 с тремя парами рабочих роликов 8 и опорных катков 9, заключенных в текстолитовые вкладыши 10. При движении сепаратора рабочие ролики катятся по деформируемой трубе, а опорные катки - по неподвижным опорным планкам. 
Сепаратор, опорные планки и опорные катки устанавливаются таким образом, чтобы рабочие ролики могли самоустанавливаться относительно оси прокатываемой трубы. Для исключения ударов роликов по трубе в зеве подачи и поворота предусмотрено уравновешивание роликов, катков и вкладышей при помощи упругого элемента (например, резины), установленного на передней и задней проводках.

Передняя лобовина сепаратора выполнена в виде съемной крышки 11, а задняя стенка имеет хвостовик с резьбой, который вставляется в торцевое отверстие в ползуне 12 и крепится к нему гайкой 13.

К ползуну 12 привинчиваются две верхние бронзовые и две нижние текстолитовые наделки 14, скользящие по внутренней поверхности сегментов. Для уменьшения сил трения на верхние сегменты через отверстия в последних подаётся густая смазка, а поверхности нижних сегментов смазываются эмульсией.

Ползун соединяется с шатунами кривошипно-шатунного механизма посредством приваренных к нему проушин.

Подача эмульсии осуществляется в верхнее окно сепаратора для охлаждения цапф роликов и катков, и спереди сепаратора для охлаждения рабочего конуса.

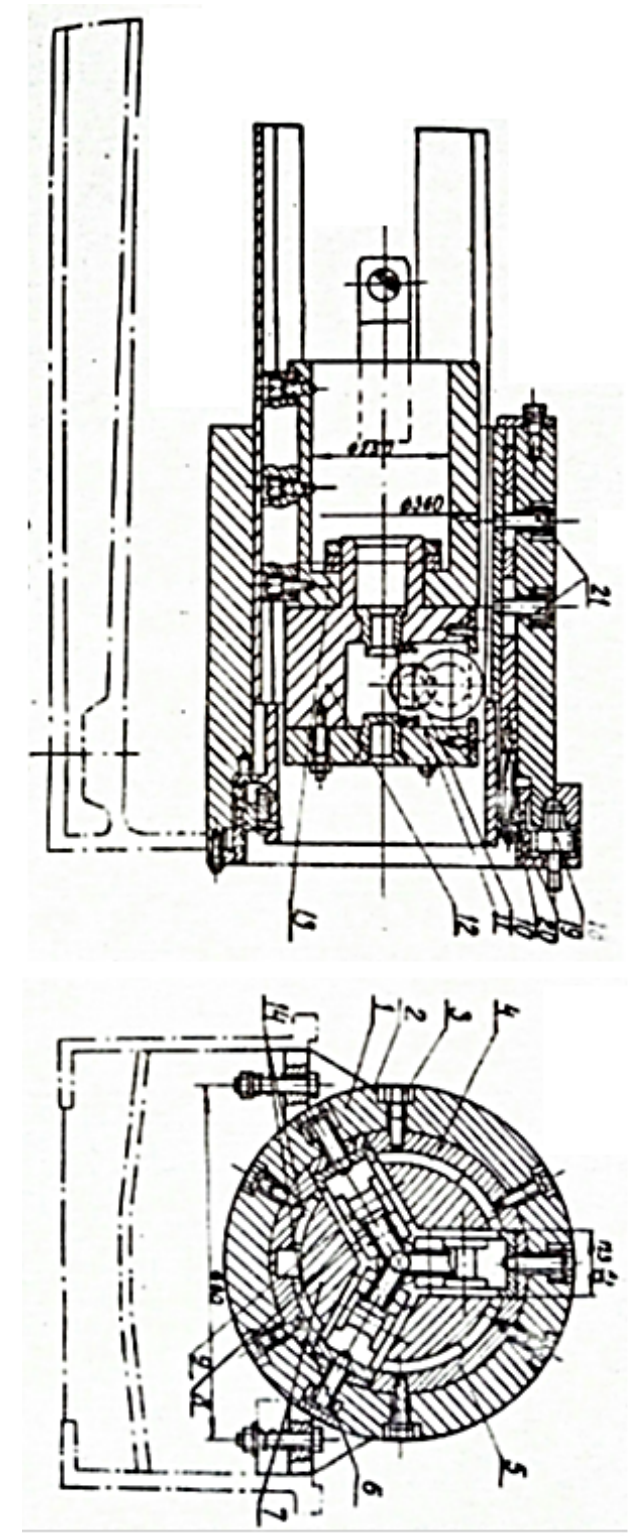

Рис. 2. Стационарная рабочая клеть стана ХПТР 15-30 
Габаритные размеры обоймы клети обеспечивают установку ее на станину действующих станов ХПТР 15-30. Крепление клети к станине осуществляется шестью болтами. На фото (рис. 3) показана клеть, установленная на стане ХПТР 15-30. В общей сложности снятие обычной клети и установка новой занимает 5-6 часов.

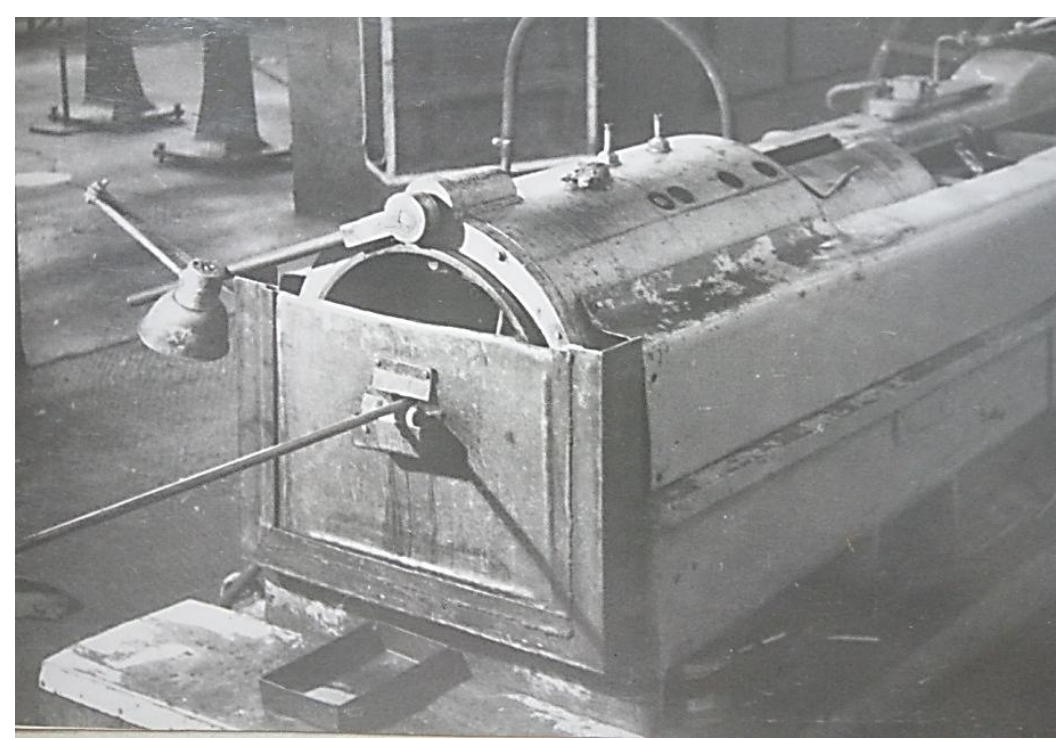

Рис. 3. Общий вид стационарной рабочей клети, установленной на стане ХПТР 15-30

Конструкция клети обеспечивает относительно быструю перевалку роликов и катков (в пределах 15-20 мин), которая производится при снятой крышке 11 сепаратора (рис. 2) извлечением верхнего комплекта инструмента, а затем - боковых комплектов.

\section{ВЫВОДЫ}

Использование стационарной клети стана ХПТР позволяет без существенного изменения конструкции стана повысить не только точность и качество поверхности труб, а также многократно и производительность стана за счет максимального нивелирования упругой деформации системы «рабочий ролик-корпус клети» при использовании неподвижной толстостенной обоймы в качестве корпуса клети, увеличения хода сепаратора в 1,7 раза, а также снижения веса подвижных частей клети более чем в 2 раза.

\section{СПИСОК ИСПОЛЬЗОВАННОЙ ЛИТЕРАТУРЫ}

1. Король Р. Н. Калибровка ручья роликов стана ХПТР для прокатки особотонкостенньх труб повышенной точности / Р. Н. Король, В. И. Кузьменко // Удосконалення прочесів та обладнання обробки тиском в металургії і машинобудуванні : темат. зб. наук. праџь-Краматорськ : ДДМА, 2007. - С. 406-411.

2. Король Р. Н. Резервы повышения точности труб, прокатанных на станах холодной периодической роликовой прокатки (ХПТР) / Р. Н. Король, И. М. Амиров // Металл и литье Украиныл. - 2007. - № 5. - С. 54-59.

3. Король Р. Н. Развитие направлений повышения точности и качества прецизионных тонкостенных и особотонкостенных труб при холодной периодической роликовой прокатке / Р. Н. Король // Металл и литье Украиньь. - 2008. - № 3-4. - C. 44-51.

4. Король Р. М. Механізми утворення не прямолінійності подовжньої осі труби в проиесі холодної періодичної роликової прокатки / Р. М. Король // Металл и литье Украиньь. - 2007. - № 11-12. - С. $58-62$.

5. Король Р. Н. Обоснование, разработка и внедрение ращиональной технологии прокатки труб повьшенной точности с использованием сварной заготовки на станах ХПТР : автореф. дис. на соискание ученой степени канд. техн. наук : спец. 05.03 .05 «Процессы и машины обработки давлением» / Р. Н. Король. - Днепропетровск, 2009. - 20 c. 